no approximate check on the course of the plane or the compass used. Nor is any clue given as to which observation may be in error in case of a discrepancy. The method provides no alternate procedure in the event only two of the three stars are observed. The old-fashioned method of plotting lines of positions may be slow and somewhat tedious, but in time, most navigators learn to interpret the lines to good advantage. The lack of similarity to earlier methods of celestial navigation is a definite disadvantage; the navigator examining Jonge's method for the first time will probably feel that he must learn an entirely new technique.

Charles H. Sumey

\title{
MATHEMATICA' TABLES-ERRATA
}

References have been made to Errata in RMT 233 (Fletcher, Miller \& Rosenhead), 240 (Bretschneider), 243 (Jahnke \& Emde, Meissel, Smith), 245 (Gupta), 247 (D. N. Lehmer), 250 (Vallarta), 255 (H.B. \& R.C.A.), 263 (Kalähne), 270 (Tea), 274 (Jonge) ; N 50 (Fadle).

70. Edwin P. ADAms, Smithsonian Mathematical Formulae and Tables of Elliptic Functions, first reprint, Washington, 1939. Compare MTAC, v. 1, p. 191, 325.

A. P. 127 , formula 6.475 , no. 2 , for $\left(2^{2} / 2 !\right) x^{2}-(24 / 6 !) x^{4}+\left(2^{2} / 10 !\right) x^{20}$, read $(2 / 2 !) x^{2}-\left(2^{2} / 6 !\right) x^{6}+(25 / 10 !) x^{10}$.

P. 136, line 2, the lower limit of the integral is 0 .

P. 197, formula 9.110, no. 2, for $C_{-1}(x)$, read $C_{v-1}(x)$; no. 4, for $d C(x) / d x$, read $d C_{\nu}(x) / d x$.

P. 199, formula 9.151, for $2\left(\frac{1}{3} x\right)$, read $2\left(\frac{1}{2} x\right)^{\gamma}$, and in the integral, for the upper limit $\pi$, read $\frac{1}{2} \pi$.

P. 203, formula 9.202, line 3 , for $J(x)$, read $J_{8 / 2}(x)$.

Radio Corp. of America

M. S. Corrington

Camden, New Jersey

B. P. 189, formula 8.708, no. 1 , for $c_{1} x$, read $c_{1} x^{\lambda}$; formula 8.709, for $\left(a+b^{2} x^{d} y\right.$, read $\left(a+b^{2} x^{3}\right) y$

U. S. Coast and Geodetic Survey

WALTER D. LAMBERT

Editorial Note: The error noted on p. 127 of $A$ was copied by L. B. W. Jolley, in formula (508) of his Summation of Series, London, 1925.

71. H. Brandenburg: 1. Siebenstellige trigonometrische Tafel ..., second ed., Leipzig, 1931, p. 336.

2. Sechsstellige trigonometrische Tafel .... Ann Arbor, Mich., 1944, p. 300 ; compare $M T A C$, v. 1, p. $387 \mathrm{f}$.

The 30-place tables in question are those of $(a)(\pi / 2)^{n} ;$ and $(b)(\pi / 2)^{n / n !}$

\begin{tabular}{|c|c|c|c|c|c|}
\hline \multirow[b]{2}{*}{ 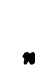 } & \multicolumn{5}{|c|}{$(\pi / 2)^{n}$} \\
\hline & For & Reed & N & Por & Read \\
\hline 7 & ..227019 & $\ldots 27125$ & 14 & $\ldots 15909$ & $\ldots 19020$ \\
\hline 8 & $\ldots 62080$ & $\ldots 62136$ & 15 & ...37037 & $\ldots 40617$ \\
\hline 9 & $\ldots 64804$ & $\ldots 64921$ & 16 & $\ldots 39780$ & $\ldots 43355$ \\
\hline 10 & $\ldots 58511$ & $\ldots 58710$ & 17 & $\ldots 12705$ & .23698 \\
\hline 11 & $\ldots 98520$ & ..988821 & 18 & $\ldots 18723$ & $\ldots 31773$ \\
\hline 12 & $\ldots 62827$ & $\ldots 63300$ & 19 & $\ldots 43830$ & ...72517 \\
\hline 13 & $\ldots 07103$ & $\ldots 07788$ & 20 & ...367066 & $\ldots 400842$ \\
\hline
\end{tabular}


The existence of errors in the 1932 edition, of the second work listed above, was referred to by $\mathrm{L} . \mathrm{J}$. C. in $M T A C$, v. 1, p. 162 , but he gave no details as to their identity.

\begin{tabular}{|c|c|c|}
\hline \multicolumn{3}{|c|}{$(\pi / 2)^{n} / n !$} \\
\hline$n$ & For & Read \\
\hline 10 & $\ldots 53002$ & $\ldots 53022$ \\
\hline
\end{tabular}

4211 Second St., N.W.

JOHN W. WRENCH, JR.

Washington 11, D. C.

72. Burroughs Adding Machine Co., Table of Reciprocals 1 to 10,000, Detroit, Michigan, 1911, 24 p. Revised ed., 1940. With a thumb index for each 1000. $22.2 \times 27.7 \mathrm{~cm}$.

In 1930 this table was compared with proofs of Barlow's Tables (MTAC, v. 1, p. 1617); the only errors found were:

$$
\begin{array}{r}
\text { Reciprocal of 118, for } 8474577 \text {, read } 8474576 \text {; } \\
185, \text { for } 5405406 \text {, read } 5405405 \text {; } \\
476, \text { for } 2100841 \text {, read } 2100840 .
\end{array}
$$

In editions of that date the argument 8260 was printed 6260 , but in the revised edition it has been corrected. The purpose of this note is not so much to call attention to these trivial errors, none of which would affect a calculation, as to point out the general correctness of the table.

This table was produced for use with the Burroughs Moon-Hopkins multiplying machine and with their key-driven calculator, in order that division might be done by multiplying by a reciprocal. It is excellent for this purpose.

L. J. C.

73. P. R. E. JAHNKE \& F. EMDE, Tables of Functions with Formulae and Curves, fourth ed., 1945. Compare $M T A C$, v. 1, p. 386, $391 \mathrm{f}$.

$A$. Besides 17 last-place unit errors I found the following other errors in the second table of powers in the Addenda, p. 8, 9:

$\begin{array}{cccc}\text { Argument } & \text { Power } & \text { For } & \text { Read } \\ .7 & .15 & .9497 & .9479 \\ .8 & .15 & .9673 & .9671 \\ .8 & .20 & .9551 & .9564\end{array}$

An additional error in this table was reported by J. C. P. MiLler, MTAC, v. 1, p. 397. JOHN W. Wrench, JR.

Editorial Notr: The errors occur also in ExdR, Tables of Elementary Functions, 1944, p. 8; see MTAC, v. 1, p. 384.

B. P. 274, for F. C. Titchmarsh, read E. C. Titchmarsh; error since the 1933 edition. P. 275, for $x^{1-\gamma / 2} e^{-a / 2} M$, read $x^{-\gamma / 2} e^{-2 / 2} M$; error since the 1938 edition.

WALTER WEINSTEIN

34 Parliament Hill

London N.W. 3, England

74. E. Meissel, "Abgekürzte Tafel der Bessel'schen Functionen $I_{z}{ }^{(k)}$," Astr. Nach., v. 128, 1891, col. 156. Compare MTAC. v. 1, p. 298. 
In this table are the following errors:

$$
\begin{aligned}
& J_{\text {wr }}(1000) \text {, for }+.00752995 \text {, read }+.00753142 \text {, } \\
& J_{\text {oud }}(1000) \text {, for }-.00526524 \text {, read - } 00526276 \text {. }
\end{aligned}
$$

My results were obtained by computing the two values $J_{1000}(1000)=.04473067295$, $J_{m}(1000)=.04883022878$, from formulas given by Meissel, and an application of the recurrence formula. For $n=981(1) 1000$, I checked his results exactly.

M. S. Corrington

\section{NYMTP, Tables of Circular and Hyperbolic Sines and Cosines for Radian} Arguments, Washington, 1939. See MTAC, v. 1, p. 45 f, 161.

On p. 337 , in the argument following the argument 1.6847 , for 1.6868 , read 1.6848 .

A. N. LOWAN

76. D. B. Smith, L. M. Rodgers \& E. H. Traub, "Zeros of Bessel functions," Franklin Institute, J., v. 237, 1944, p. 301-303. Compare $M T A C$, v. 1 , p. $213,215,217,218,274,305$. On this last page we quoted the authors' statement on p. 303, that these tables are believed to be "accurate to the extent that the last figure is within plus or minus two of the correct value." On 4 June 1945, Mr. M. S. Corrington (see MTAC, v. 1, p. 212, 285 and RMT 222) drew our attention to serious discrepancies between results of these authors and those of G. N. WATSON and J. R. Airey. Resulting investigations led to the following report:

The whole of Table II has been compared with BAASMTC results, obtained for $x<25$ by Mr. S. Johnston, see MTAC, v. 1, p. 284, BAASMTC 9. This has confirmed the three major errors found by Corrington:

$$
\begin{aligned}
& j_{2,7} \text { for } 24.27112 \text {, read } 24.27011 \text {, } \\
& j_{1,} \text { for } 24.1990, \text { read } 24.0190 \text {, } \\
& j_{h, 1} \text { for } 8.77142 \text {, read } 8.77148 \text {. }
\end{aligned}
$$

Three other changes were also indicated, but in each case the value given is within a unit of the true value. Other values are correct; in particular $j_{2}$, and $j_{2,5}$ are correct, Watson's values being in error (see MTE 78).

For Table I, no BAASMTC results are yet available, except for $n=0$ (which gives the same zeros as $n=1$ in Table II), but for $n \leqslant 4$ a comparison was made with another table available to the writer. For $n>4$, the columns of values were differenced, together with the values for $n \leqslant 4$; this provided a complete check on the run of the values, as the differences are well-behaved, especially so for high $n$. The final digit is not completely checked in this way but, apart from three errors listed below, it is certainly within the limit claimed by the authors, and almost certainly within one final unit, i.e. of the fourth decimal, of the true value. Finally the last value in each column for $s=1(1) 7$ (the last 4 values for $s=5$ ) were recomputed from the equation $J_{n-1}(x)=J_{n+1}(x)$, using the BAASMTC 10-decimal table of $J_{n}(x)$ at interval 0.1 in $x$ (see MTAC, v. 1, p. 283, BAASMTC 2). This was done either by inverse interpolation, or by use of the approximate formula

$$
j_{n=}^{\prime}=x+\frac{x^{2}}{x^{2}-n^{2}} u-\frac{x^{2}\left(x^{2}+n^{2}\right)}{2\left(x^{2}-n^{2}\right)^{3}} u^{2}+\cdots
$$

in which $x$ is an approximation (here a multiple of 0.1 ) to the zero, and $u=J_{n}^{\prime}(x) / J_{n}(x)$. 
Three major errors were found:

$$
\begin{aligned}
& j_{2,}, \text { for } 22.6721, \text { read 22.6716, } \\
& j_{h,} \text { for } 24.1469 \text {, read 24.1449, } \\
& j_{h,} \text { for } 23.8033 \text {, read } 23.8036 \text {. }
\end{aligned}
$$

Five other changes (there may be more) were also indicated, but each value given is already within a unit of the true value.

In two tables giving 164 values in all (only 156 distinct and non-trivial) there are thus 6 major errors. This is too high a proportion and, in the present age of calculating machines and of the production of large books of mathematical tables with a good chance of being error-free, it seems to the writer that it is time both that (a) authors of small tables should make certain that the tables are accurate (a table is not easy to compute unless it is easy to check by an independent method), and that (b) editors should do their utmost to choose a referee who is willing to check the tabular material, especially if the table is of general importance.

\section{August 1945.}

J. C. P. MrLeR

Edrtorial Note: On Aug. 13, 1945, Mr. M. S. Corrington also drew our attention to the fact that the tables of Smith, Rodgers \& Traub were reprinted in Electronics, v. 17, July 1944, p. $240,244,248$. Hence the above criticisms apply equally to this reprint.

77. U. S. Hydrographic Office, Useful Tables. From the American Practical Navigator, H.O. 9, part II, Washington, D. C., 1911. Tables of Logarithmic and Natural Haversines, p. 817-921.

As a result of an entire recomputation of the Haversine tables taken from this work (described $M T A C$, v. 1, p. 421-422), I have to report that the above Hydrographic Office table contains at least 230 unit errors in the last decimal place and the following more serious errors:

$\begin{array}{lccc}\text { Page } & \text { Angle } & \text { For } & \text { Read } \\ 818 & 2^{\circ} 52^{\prime} & 6.79630 & 6.79636 \\ 821 & 11^{\circ} 09^{\prime} & 7.97478 & 7.97487\end{array}$

University of Colorado

Boulder

Charles A. Hutchinson

78. G. N. Watson, A Treatise on the Theory of Bessel Functions. Cambridge, University Press, 1922. Second ed., Cambridge, University Press, and New York, Macmillan, 1944. See $M T A C$, v. 1, p. 296, 307, 364, 367. The editors received from $H$. W. SANDERS of the Univ. Adelaide a list of 50 errors in the text of the first edition, but not affecting tabular material, copied from the late J. R. Wilton's copy of this work.

The following list of errata is the result of a fairly systematic, but incomplete, examination of the numerical tables by comparison with other tables, published and unpublished. The unpublished tables are mainly ms. tables prepared for future BAASMTC volumes. It would take a long time to complete the checking of all the tables in Watson's book, so that it seems worth while to give an interim list. It also seems worth while, on the other hand, to include all major errors, even if they have been noted previously in this journal. Besides errors in the numerical tables, the list includes also some errors in the text that are known to the writer, and two of the corrigenda given by Watson himself in the first edition, but often overlooked. 


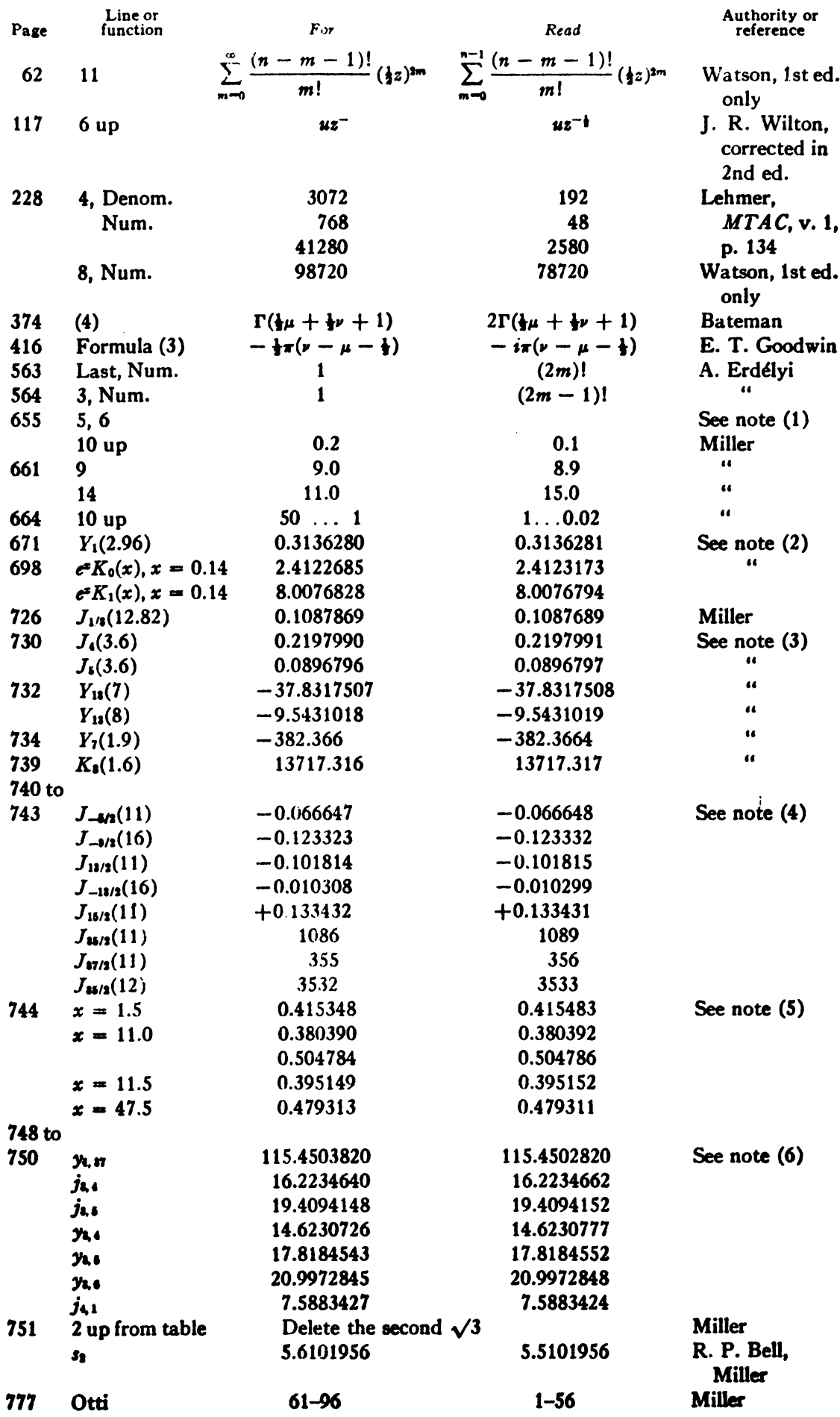




\section{Notes}

(1) Confusion here; both Hansen and Schlömilch give the table for $\$ x=0(.05) 10$, Lommel's table is for $x=0(.1) 20$, and is not an extension. See MTAC, v. 1, p. 194, MTE 29.

(2) These errors were noted in BAASMTC, Bessel Functions, Part $I$, p. xvii. All are corrected in the second edition, the correction to $Y_{1}(2.96)$ being trivial.

(3) All of Table IV has been compared with BAASMTC ms. tables, with the exception of the tables of $e^{-x} I_{n}(x)$ on page 736. All errors found are listed.

(4) The table of $J_{ \pm(n+1)}(x)$ for $x \leqslant 20$ was compared with Airey's table in the B.A.A.S., Report for 1925 ; for $x>20$, the table is unchecked. All discrepancies of a unit or more in the sixth decimal have been listed; there are also 42 others less than a unit in amount. The error in $J_{-0 / 3}(16)$ was noted by Airey.

(5) Given by J. W. Wrench, Jr., MTAC, v. 1, p. 366, MTE 58; they were known to Airey for $x \leqslant 20$. Wrench also gives 26 further changes of a unit in the sixth decimal.

(6) These discrepancies were found by comparison with BAASMTC ms. tables, by S. Johnston and the writer. Eight other discrepancies of a unit were also noted. The ms. tables have not yet been fully checked, so that this list must be regarded as provisional.

J. C. P. MnLER

\section{UNPUBLISHED MATHEMATICAL TABLES}

Reference has been made to an unpublished table in RMT 262 (Great Britain), 263 (Carsten \& McKerrow), 266 (Great Britain), 267 (Great Britain), QR 20 (Miller \& Johnston).

39[B]. - Table of Powers of $z=x+i y$. Manuscript prepared by, and in possession of, the NYMTP.

This ms. gives the exact values of $z^{n}$ for $n=1(1) 25, z=x+i y$, where $x$ and $y$ each ranges from 0 through 10 at unit intervals.

\section{A. N. Lowan}

40[L].-Enzo CaMBI, Tables of $J_{n}(x)$. Manuscript in the possession of the author, a doctor of engineering, Via Giovanni Antonelli 3, Rome, Italy.

These are tables that $I$ have calculated in recent years. The first contains $J_{n}(x)$ for $x=[0(.001) .5 ; 15 \mathrm{D}]$ and $n=1(1) 11$, that is to say, to that value of $n$ where $J_{n}(0.5)$ is of the order of $10^{-15}$. Such a table, in conjunction with the well-known addition formula for the Bessel functions, and, for instance, with Meissel's table of $J_{n}(x)$ for integral values of $x$ up to 24 (see $M T A C$, v. 1, p. 216), makes it possible to calculate directly $J_{n}(x)$ for $x=[0(.001) 24.5 ; 15 D]$.

The second table gives $J_{n}(x)$ for $x=[0(.01) 10.5 ; 10 \mathrm{D}]$ and $n=1(1) 29$. By the use of this table it is possible to compute easily the value of any function given in the form of a Neumann series of Bessel functions for $x=[0(.01) 10.5 ; 9$ or 10D]. This range of $x$ covers the field of most applications in physics.

For the main table, values of $J_{n}(x)$ for $x=0(.05) 10.5$ were first computed to 12D, for even $n$ up to $x=1.5$, power series being used; for higher values of $x$, derivatives at unit interval of $x$ formed from Meissel's table were used to get values at interval .05 with the aid of Taylor's series. These were checked by differencing, subtabulated to interval .01, and the final values checked by

$$
J_{0}+2 J_{2}+2 J_{1}+2 J_{0}+\cdots=1 .
$$

Values for odd $n$ were formed by recurrence and checked by

$$
J_{1}+3 J_{2}+5 J_{6}+7 J_{7}+\cdots=1 x^{2}
$$

